\title{
FORMAÇÃO PARA ENSINO DE PROBABILIDADE E ESTATÍSTICA NO BRASIL
}

\author{
Lucicleide Bezerra \\ Universidade Federal Rural de Pernambuco - FRPE, Brasil \\ lucicleide_bezerra@hotmail.com
}

Esse artigo é um recorte da nossa pesquisa de mestrado que investigou a formação para o ensino da Estatística e Probabilidade, nos currículos dos cursos de Licenciatura em Matemática no Brasil. Nesse recorte apresentaremos apenas os resultados das análises realizadas nas matrizes curriculares e nos ementários. Mapeamos os cursos e realizamos uma amostra com estratos proporcionais em todas as regiões e redes de ensino, públicas e privadas. Investigamos 78 cursos, distribuidos em 48 Instituições de Ensino Superior. Coletamos matrizes curriculares, Projetos Politicos Pedagógicos, Ementários, Programas de disciplinas e aplicamos um questionário com coordenadores dos cursos. Os resultados mostram que os componentes curriculares de formação conceitual em Estatística e Probabilidade estão presentes nas matrizes curriculares dos cursos de $L M$ de forma obrigatória, independente da região, estado, município ou rede de ensino, todos os cursos analisados têm a preocupação em ter em seu currículo prescrito o ensino conceitual de tais conteúdos.

A Estatística está presente nas mais diversas áreas da sociedade, levantando e apresentando dados sobre as condições de segurança, saúde, socioculturais e políticas. Tal presença trouxe consigo uma necessidade de ensino dessa ciência para um número cada vez maior de pessoas. Com isso, nos últimos anos, a maioria dos países introduziu em seus programas de matemática, conteúdos de Estatística, como um dos componentes curriculares (Lopes, 1998).

Segundo Bezerra (2014):

No Brasil, desde a década de 90, os documentos oficiais já incorporam orientações para inclusão da formação Estatística como campo da Matemática Escolar. Os Parâmetros Curriculares Nacionais do Ensino Fundamental e do Médio de Matemática (Brasil, 1997, 1998, 1999), assim como as Orientações Curriculares do Ensino Médio (Brasil, 2006), contém recomendações para o ensino no bloco Tratamento de Informações no Ensino Fundamental e no eixo Análise de Dados e Probabilidade no Ensino Médio, que inclui os tópicos de Probabilidade e Estatística.

Ainda que a inserção da Estatística seja recomendada nas propostas curriculares de Matemática em diversos países, na maioria deles, existe uma insatisfação com o ensino desse componente curricular (Lopes, Coutinho e Almouloud, 2010).

Decidimos portanto investigar os currículos dos cursos de Licenciatura em Matemática no Brasil e descrever um panorama relativo a formação para o ensino da Estatística e Probabilidade na Educação Básica. Verificando, em meio a outras questões, se cursos de Licenciatura em Matemática no Brasil que contemplam em seus currículos a formação para o ensino da Estatística e Probabilidade, se tais componentes estão presente de forma obrigatória e verificar nos componentes curriculares de educação e relativos à prática pedagógica, tais como de: currículo, didática, epistemologia, história e filosofia, pesquisa ou metodologia da pesquisa, prática/estágio, psicologia, tecnologia, aspectos diferenciados que possam influenciar na formação do professor para ensinar Estatística;

Quando nos referimos a currículo estamos falando de toda uma construção com todas as formas de visualizar pois, "o currículo não é um conceito, mas uma construção cultural, é um modo de organizar uma série de práticas educativas” (Grundy, 1987, apud Sacristán, 2000).

\section{A ESTATÍSTICA E DA PROBABILIDADE NAS ORIENTAÇÕES OFICIAIS}

Segundo Bezerra (2014) em 2015, completam vinte anos da "publicação da versão preliminar dos Parâmetros Curriculares Nacionais (PCN) (Brasil, 1995) para o Ensino Fundamental no Brasil, posteriormente em 1997 e 1998, respectivamente, os Parâmetros Curriculares Nacionais $(\mathrm{PCN})$ de $1^{\mathrm{a}}$ a $4^{\mathrm{a}}$ séries e de $5^{\mathrm{a}}$ a $8^{\mathrm{a}}$ séries (equivalente do $1^{\mathrm{o}}$ ao $9^{\circ}$ anos) ... a lei incumbia à União, em colaboração com os estados, Distrito Federal e municípios, a responsabilidade de estabelecer currículos e conteúdos mínimos para a Educação Básica no Brasil (p.21)." 
Ainda segundo a autora "Nos Parâmetros Curriculares Nacionais do Ensino Fundamental (PCNEF) temos quatro blocos: Números e Operações, Espaço e Forma, Grandezas e Medidas e Tratamento da Informação (inclui Combinatória, Probabilidade e Estatística). Nesse nível de ensino, os PCN sugerem que o estudante deveria entrar em contato com as noções de Estatística Descritiva" (p.22).

No PCN de matemática para o Ensino Médio (Brasil, 2000), a divisão acontece em três blocos: Álgebra: Números e Funções, Geometria e Medidas e Análise de dados (inclui Contagem, Probabilidade e Estatística).

As Diretrizes Curriculares Nacionais (DCN) (Brasil, 2002a):

limitam a obrigatoriedade da presença dos conteúdos relativos ao estudo de Probabilidade e Estatística aos cursos de bacharelado, não havendo qualquer indicação explícita de abordagem de tais assuntos para os cursos de licenciatura, menciona apenas que para a licenciatura serão incluídos, no conjunto dos conteúdos profissionais, os conteúdos da Educação Básica, consideradas as Diretrizes Curriculares Nacionais para a formação de professores em nível superior, bem como as Diretrizes Nacionais para a Educação Básica e para o Ensino Médio. Portanto, os coloca indiretamente no âmbito dos conteúdos profissionais (Bezerra, 2014. p. 23).

\section{RESULTADOS E DISCUSSÕES}

Os estados com maior concentração de cursos autorizados estão nas regiões Sul e Sudeste, são eles: São Paulo com 75 cursos, Rio Grande do Sul com 36, Rio de Janeiro com 35, Minas Gerais com 34 e Paraná com 23.

Quando analisamos a distribuição dos cursos por rede de ensino e por região, as regiões Sul e Sudeste têm predominantemente cursos da rede privada de ensino, enquanto nas regiões Nordeste, Norte e Centro-oeste a predominância são os cursos da rede pública de ensino. Conforme é possível observar no Gráfico 1.

Gráfico 1- Distribuição dos cursos por Região e por Rede de Ensino (Percentual)

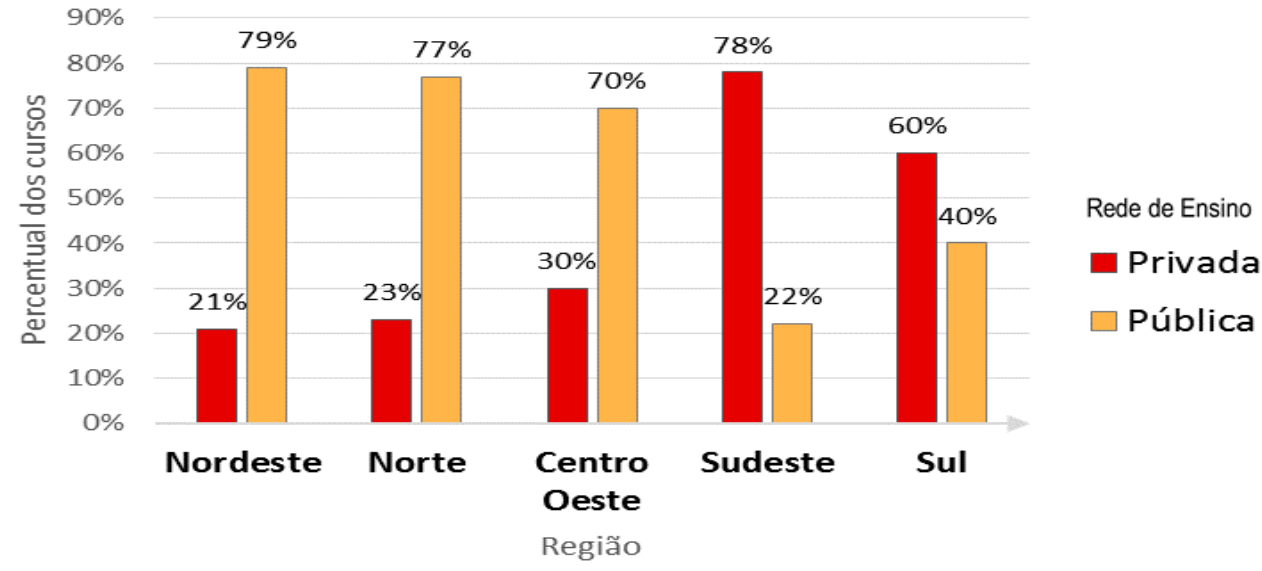

Constituída a amostra composta por 78 cursos, distribuídos em 48 IES, realizamos a coleta das matrizes das curriculares nos sites das IES. Foi possível coletar os dados seguindo o plano amostral.

Identificamos que em todas as 48 IES possuem disciplinas de conteúdos estatísticos e/ou probabilísticos como componentes obrigatórios, ver Tabela 1. A maioria dos cursos com apenas 1 componente de Estatística e/ou Probabilidade. 
Tabela 1 - Componentes Curriculares de conteúdos Estatísticos e/ou Probabilísticos

\begin{tabular}{|l|r|}
\hline Nome do Componente Curricular & Quant \\
\hline Educação Estatistica & 1 \\
\hline Análise Combinatória e Probabilidade & 3 \\
Elementos da Estatística & 1 \\
\hline Estatística & 10 \\
Estatística Aplicada à Educação & 3 \\
\hline Estatística B & 1 \\
Estatística Descritiva & 5 \\
Estatística Educacional & 1 \\
Estatística I & 2 \\
Estatística I e II & 3 \\
Estatística para Licenciatura & 1 \\
Estatística Probabilística & 3 \\
Introdução à Estatística & 2 \\
Introdução à Estatística e Probabilidade & 1 \\
Introdução à Probabilidade & 1 \\
Métodos Estatísticos & 4 \\
Probabilidade & 17 \\
\hline Probabilidade e Estatística & 3 \\
Probabilidade e Estatistica Ie II & 1 \\
\hline Probabilidade e Inferência Estatística & 1 \\
\hline Tratamento da Informação & 66 \\
\hline Total &
\end{tabular}

Fonte: dados da pesquisa (2013)

Classificamos os demais componentes curriculares dos cursos pela matriz curricular, usando como critérios aspectos diferenciados que podem influenciar na formação do professor de forma a contribuir para ensino e aprendizagem da Estatística e Probabilidade, como mapeamento para localizar, a partir das ementas, aspectos estatísticos nas disciplinas que tratam de currículo, didática, epistemologia, história-filosofia, pesquisa, prática, psicologia e tecnologia.

Nos componentes curriculares de currículo, epistemologia, história e filosofia e de psicologia não foi possível observar nenhum elemento que favoreça de maneira direta a formação para a Estatística e Probabilidade.

\section{OBSERVAÇ̃̃O DE ALGUM PRINCÍPIO DEFENDIDO NA EDUCAÇ̃̃O ESTATÍSTICA}

O ensino da Estatística e da Probabilidade deve valorizar princípios como os da pesquisa, o aluno como sujeito ativo de todo o processo e todas as etapas da pesquisa, a transdisciplinaridade, representando um nível de integração que vai além da interdisciplinaridade, não existindo fronteira entre as disciplinas. Para isso a contextualização constitui-se num recurso eficiente que o professor pode dispor para favorecer a aprendizagem de conteúdos da Estatística e da Probabilidade, no desenvolvimento de conhecimentos estatísticos por parte dos alunos. Tudo auxiliado pela tecnologia, favorecendo a integração do conteúdo e prática, facilitando a organização, análise e apresentação dos dados.

Portanto um ensino que tenha como princípios: a pesquisa, a contextualização, a integração da teoria e prática, a transdisciplinaridade e o uso das tecnologias digitais busca pensar no que devemos esperar para o ensino e para a aprendizagem da Estatística e Probabilidade, para termos cidadãos críticos, capazes de exercer plenamente sua cidadania, tendo condições de fazer uma leitura crítica do mundo.

Ficou evidente na análise que a maioria das referências encontradas, quanto aos princípios, estão nos componentes de conteúdo específico (Estatística e Probabilidade), 71\% dos componentes que possuem e $17 \%$ dos que podem possuir algum princípio.

Quando analisamos os componentes curriculares que possuem ou podem possuir algum princípio por região percebemos que na Sudeste existe uma maior ênfase na pesquisa e no Sul o componente que aparece contendo mais princípios são os componentes da didática, como é possível observar no Gráfico 2. 
Gráfico 2 - Percentual de ocorrências nos Componentes Curriculares que possuem ou podem possuir algum princípio da EE por região

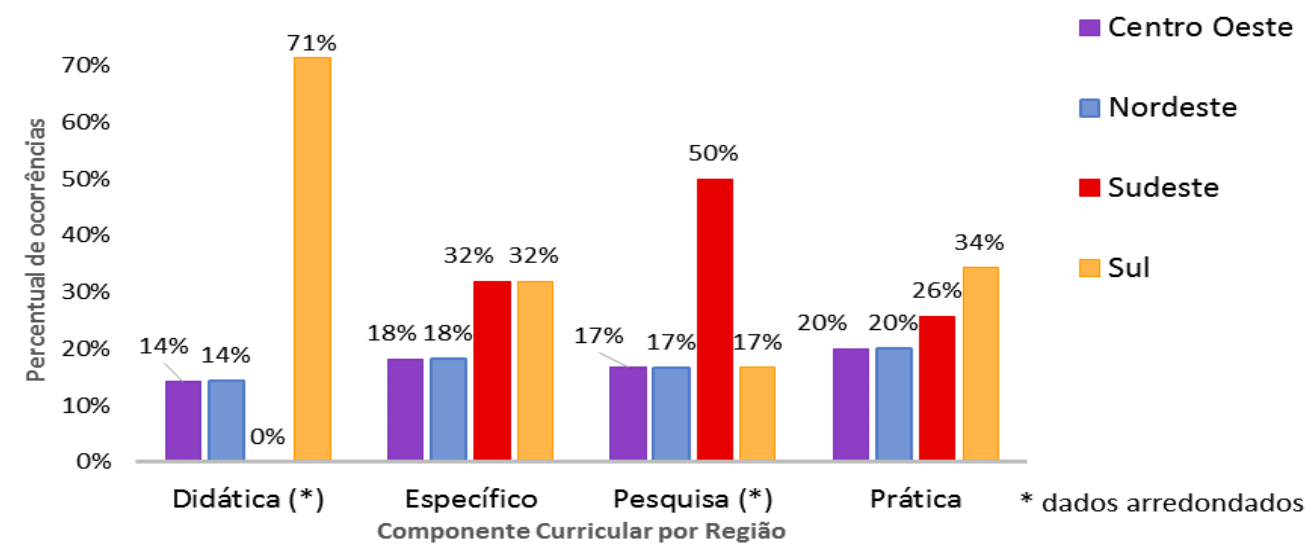

Fonte: dados da pesquisa (2013)

Categorizamos possuir princípios da Educação Estatística, componentes curriculares de conteúdo específicos (Estatística e/ou Probabilidade) ou não, que trouxessem a preocupação com qualquer um dos princípios, de forma isolada ou em mais de um princípio na mesma ementa, quer fossem princípios: da pesquisa, da contextualização, interdisciplinaridade, integração de conteúdo + prática.

Na ementa de componente específico de introdução à Estatística e Probabilidade da IES 4.4.1 classificamos como possuir algum princípio, pois em seus objetivos trazia a preocupação em que os alunos produzissem pesquisas estatísticas a partir de dados e interpretá-los e o uso de tecnologia, conforme as ementas:

\section{Introdução à Estatística e Probabilidade}

Objetivos: Introduzir os princípios de Estatística, capacitando o aluno a: ler e interpretar trabalhos que envolvam análises elementares; elaborar estatísticas, a partir de dados primários, interpretá-los na reflexão sobre seu próprio trabalho; ministrar os conteúdos da disciplina para futuros educadores de $1^{\circ}$ e $2^{\circ}$ graus; saber quando e como consultar especialistas da área de Estatística. (grifo nosso) (IES 4.4.1)

Outra ementa selecionada como possuir algum princípio da EE foi a ementa da Educação Estatística da IES 5.1.2, embora na ementa não traga os objetivos e a forma que se deseja trabalhar os conteúdos, o título do componente (Educação Estatística) nos remete a preocupação com o alcance das metas da EE.

\section{Educação Estatística}

Ementa: Conceitos básicos de estatística; técnicas de amostragem; medidas de posição; dispersão; assimetria; curtose; teoria das probabilidades; tratamento da informação. (IES 5.1.2)

Nos componentes de didática da IES 4.4.1 (IES particular do Sudeste), traz a preocupação com a formação de um cidadão crítico reflexivo, a modelagem matemática, o uso de tecnologia aliado ao ensino da Estatística e Probabilidade.

Instrumentação para o Ensino da Matemática A

Objetivos: Pretende-se que o licenciando desenvolva reflexões críticas a respeito das interações entre a Matemática e os processos de ensinoaprendizagem na escola atual, e adquira habilidade no preparo de uma unidade didática e na pesquisa de recursos didáticos para o seu desenvolvimento no âmbito do Ensino Fundamental.

Conteúdo programático: Reflexões sobre o que é Matemática, a matemática que se aprende e a que se ensina, os objetivos de seu ensino no Ensino Fundamental (5 $5^{\mathrm{a}}$ a $8^{\mathrm{a}}$ séries). Apresentação de diversos métodos (resolução de problemas, uso da História da Matemática, uso de materiais 
didáticos e recursos tecnológicos, modelagem matemática, dentre outros) para o ensino de Matemática com vistas ao planejamento de unidades didáticas. Implementação por meio de aulas simuladas das aulas preparadas. A temática das aulas simuladas abrangerá os campos da Aritmética, Álgebra, Geometria, tratamento da informação, princípios de combinatória e probabilidade. (IES 4.4.1) (grifo nosso)

Nos componentes ligados a prática em estágio supervisionado da IES 5.1.1 (IES particular do Sul) encontramos a preocupação com a contextualização, interdisciplinaridade e a integração da formação teórica e a vivência profissional, não se referindo diretamente a Estatística, mas como princípio no projeto a ser executado:

Estágio Supervisionado II - Análise dos problemas concretos do processo de ensino-aprendizagem e da dinâmica própria do espaço escolar, da Matemática no ensino médio. Observação e participação em regência de classe, incluídas ações relativas a planejamento, análise e avaliação do processo pedagógico, vinculando a formação teórica e início da vivência profissional, supervisionada pela instituição formadora. Desenvolvimento de projetos relativos a Matemática contextual e interdisciplinaridade, junto a colégios do município. (IES 5.1.1) (grifo nosso)

O resultado da análise nos ementários aponta que, não só os componentes curriculares específicos possuem a preocupação com a formação estatística e probabilística dos futuros professores de matemática, já é possível notar que nos currículos prescritos, em componentes de didática, de estágio, uma formação não só conceitual, mas pautada em desenvolvimento de projetos contextualizados e interdisciplinar, assim como a prática de pesquisa.

\section{REFERENCES}

Bezerra, L. (2014). A Estatística e a Probabilidade nos currículos dos cursos de Licenciatura em Matemática no Brasil. Dissertação de Mestrado. Centro de Educação-EDUMATEC. p. 127.

Brasil. (1997). Secretaria de Educação Fundamental. Parâmetros Curriculares Nacionais: Matemática $\left(1^{\circ}\right.$ e $2^{\circ}$ ciclos do Ensino Fundamental). Brasília: MEC/SEF.

Brasil. (1998). Secretaria de Educação Fundamental. Parâmetros Curriculares Nacionais: Matemática $\left(3^{\circ}\right.$ e $4^{\circ}$ ciclos do Ensino Fundamental). Brasília: MEC/SEF.

Brasil. (2000). Ministério da Educação. Secretaria de Educação Média e Tecnológica. Parâmetros Curriculares Nacionais (Ensino Médio). Brasília: MEC.

Lopes, C. E., Coutinho, C., e Almouloud, S. A. (Org.). (2010). Estudos e reflexões em Educação Estatística. Campinas, SP: Mercado de Letras.

Sacristan, J. G. (2000). El curriculum: Una reflexión sobre la pratica. Madrid: Morada. 